\title{
Primary Duodenal Adenocarcinoma Revealed by Chronic Iron Deficiency Anemia: Diagnostic Difficulties in a Case Report in Internal Medicine CNHU HKM-COTONOU
}

\author{
Angèle Azon-Kouanou', Djimon Marcel Zannou', Aboudou Raïmi Kpossou², \\ Kouessi Anthelme Agbodande', Roberto Dossou Torès Kouassi Prudencio', Jean Sehonou', \\ Gaspard Gbessi ${ }^{3}$, Freddy Gnangnon ${ }^{3}$, Gabriel Ade1, Fabien Houngbe ${ }^{1}$ \\ ${ }^{1}$ Internal Medicine and Medical Oncology Department, National Teaching Hospital (NTH), Hubert Koudougou \\ Maga (HKM), Cotonou, Benin \\ ${ }^{2}$ Hepato-Gastroenterology Department, National Teaching Hospital (NTH), Hubert Koudougou Maga (HKM), \\ Cotonou, Benin \\ ${ }^{3}$ Visceral surgery Department, National Teaching Hospital (NTH), Hubert Koudougou Maga (HKM), Cotonou, \\ Benin \\ Email: angele.azonkouanou@gmail.com,djmzannou@yahoo.fr, kpossou.raimi@yahoo.fr, agbotem@yahoo.fr, \\ prudenciotores@gmail.com, jsehonou@yahoo.fr, gaspard.gbessi@gmail.com, fregnang@yahoo.fr, \\ gabriade@yahoo.fr, fab2012jos@yahoo.com
}

Received 24 October 2015; accepted 29 November 2015; published 2 December 2015

Copyright (C) 2015 by authors and Scientific Research Publishing Inc.

This work is licensed under the Creative Commons Attribution International License (CC BY).

http://creativecommons.org/licenses/by/4.0/

(c) (i) Open Access

\section{Abstract}

The location of a primary duodenal adenocarcinoma is exceptional. Only few cases have been reported in the literature. We hereby report a case of primary adenocarcinoma of the duodenum with a 60 years old patient admitted because of chronic iron deficiency anemia. Endoscopic examination revealed a budding and ulcerated process in the second duodenum. The biopsy analysis showed primary adenocarcinoma. No other primary tumor was found. The staging directed showed cephalic pancreatic invasion. The patient died in the aftermath of a surgical management.

\section{Keywords}

Chronic Iron Deficit, Adenocarcinoma, Duodenum, Benin 


\section{Introduction}

Duodenal adenocarcinoma is uncommon. It accounts for about 50\% of small bowels cancers which are also rare, as they account for less than 2\% [1]. In fact, D2 cancer ethiopathogeny is based upon the existence of many risk factors such as familial adenomatous polyposis. There are other risk factors namely: Lynch syndrome, Crohn disease, peptic ulcers, cystic fibrosis, tobacco, alcohol, cholecystectomy [2]-[4]. Based on medical history, the patient was consulted several times for gastric ulcer and chronic anemia without any diagnosis; this largely explains the late diagnosis. In case of late diagnosis, the prognosis is generally fatal and living beyond 5 years is less than 30\% cases, with an average duration of 19 months [3]. We hereby report a case of D2 adenocarcinoma whose diagnosis was conducted only after morphological examinations and repeated X-ray.

\section{Case Presentation}

This is a 60-year-old woman, who was hospitalized in the internal medicine department for etiological chronic anemia. In her medical history, there was neither diabetes nor cancer. She didn't take alcohol. There was no family history of either cancer or diabetes. Dating back to the beginning, three months before the admission was characterized by asthenia associated with mucocutaneous pallor. The gradual worsening of symptoms marked characterized by severe deterioration in general condition with anorexia, asthenia, abdominal pain including burning and recurrent anemia, has motivated her hospitalization in Internal Medicine Department.

In her medical history there was documented gastric ulcer. Physical examination revealed general poor condition with a performance status at level 3 and decompensated clinical anemia requiring multiple transfusions of red blood cells. Blood count showed anemia $(\mathrm{Hb}=5.8 \mathrm{~g} / \mathrm{dl})$ microcytic hypochromic and low serum ferritin (15 $\mathrm{ng} / \mathrm{ml})$.

Oesogastro-duodenal endoscopy revealed an atrophic fundus and bulbar duodenal erosion with no visible duodenal abnormality. Pathological examination of the corpus biopsies revealed chronic inflammation. Colonoscopy brought to light grade II internal hemorrhoids that were ligated under anuscopic control. She was readmitted 07 months later for an occlusive syndrome. A new upper endoscopy revealed a budding and ulcerated process at the second duodenum (D2) (Figure 1). The histological examination of biopsies conducted by a highly-ranked anatomy and pathology specialist revealed adenocarcinoma. The abdominopelvic x-ray with contrast-injection confirmed this duodenal tumor at pancreatic cephalic invasion stage, Figure 2. Surgical indication was required. But during surgery the tumor was ineradicable. The post-operative complications were glazed type respiratory distress and shock resulting in death after 15 days.

\section{Discussion}

Adenocarcinoma of the duodenum is uncommon. However, it is the most common neoplastic involvement of the small intestine [1]. It is the most common histological type (50\%), followed by endocrine tumors (31\%), lymphoma (20\%) and sarcomas (9\%) [5]. The incidence of duodenal adenocarcinoma is increasing since the first case described by Hamburger in 1746 [6] [7]. In a study of 346 tumors of the small intestine from the register of digestive cancers of the Gold Coast during the period 1976-2001, the annual incidence rate increased over the last ten years with a predominance for males with sex ratio of 2/1 [6]. The Age of onset is after 60 years in most

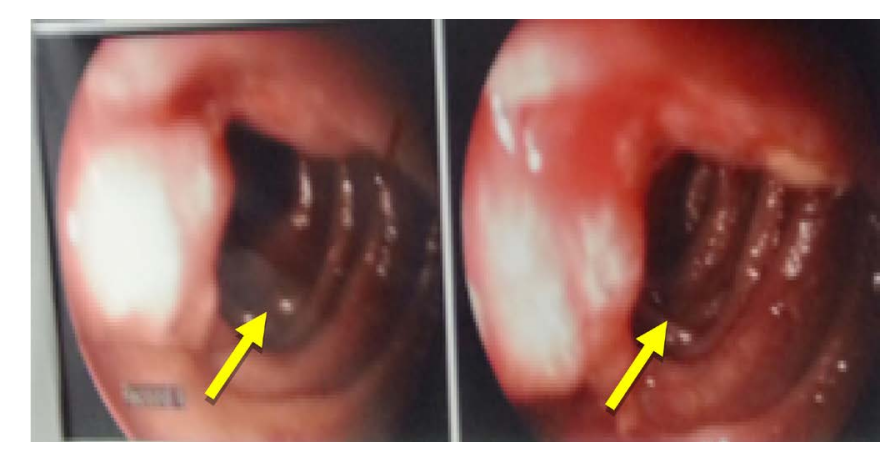

Figure 1. Endoscopic images showing the process of budding and ulcerated tumor of the anterior surface of the second duodenal. 


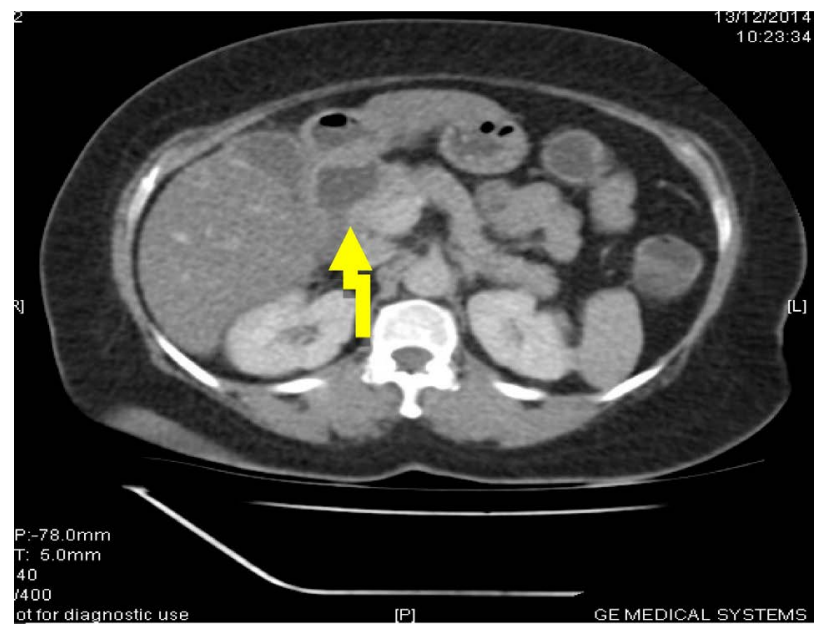

Figure 2. Tomodensitometry findings of tumor invasion of the second duodenalwith pancreatic head.

cases [8] [9]. Epigastric pain is the most common symptom [10]. The other types are: cholestatic jaundice in 31\% of cases [11], upper gastrointestinal hemorrhage, late post prandial vomiting [10], an occlusive syndrome especially in sub-papillary forms, loss of weight and finally completely asymptomatic forms are described [11]. Chronic iron deficiency anemia (for occult bleeding) as in our case is rarely revealing. But when it is present, it is generally associated with duodenal stenosis [12] [13]; which is a factor of poor prognosis [4]. The result of the clinical examination depends on the type of tumor and its characteristics (size, location, extension) it can be entirely normal, causing the delay in diagnosis [14].

The diagnosis of duodenal adenocarcinoma is based on the upper endoscopy, which allows describing the injury and biopsies in search of histological evidence [1]. In our patient, the first endoscopy did not identify the tumor. This shows the need to resume upper gastro intestinal endoscopyin case of persistent iron deficiency anemia when initial endoscopic investigations (gastroscopy and colonoscopy) are negative. The trap here was to consider anemia as the cause of internal hemorrhoids.

The preferred treatment of duodenal adenocarcinoma remains surgical, calling whenever it is possible for radical resection. This is the cephalic duodeno-pancreatectomy (DPC) which has the advantage of removing "block" the lesion and lymphatic drainage [4]. However, some authors emphasize the benefit that duodenal segmental resections would present. This would have identical results with the DPC in terms of survival with lower operative mortality; but they are reserved for lesions up to the 3rd and 4th duodena [15]. For unresectable tumors, due to mesenteric vascular invasion, or a major extension to adjacent organs like the case of our patient, or peritoneal carcinomatosis or distant metastasis, finally, we cannot use that simple derivations, type biliarydigestive gastroenterostomy or diversion with an average survival of six (06) months [16] [17]. The role of adjuvant chemotherapy is still sketchy though, according to some authors it increases survival in the medium to long term [18]. Before an adenocarcinoma, we should carry out a screening investigation of other cancers that may be associated or occur on the same lot by a colonoscopy or by genetic study [3].

\section{Conclusion}

Primary duodenal adenocarcinoma is uncommon but not unusual. Etiological investigation from senior citizens can be surprising, and that is the case of our patient. The diagnosis was late and required several morphological examinations as well as imaging for confirmation. When the clinical picture lacks distinctive characteristics leading to a cancer of the digestive tract, the diagnosis is late and the prognosis is generally fatal. In this context of chronic iron deficiency anemia, it is important to examine the second duodenum. A normal upper fibroscopy does not exclude cancer, especially in this context. Examinations have to be taken several times.

\section{Conflicts of Interests}

Authors Report no Conflict of Interest, and the permission of the family has been received for the publication of this observation. 


\section{References}

[1] Haoues, N., Bouhafa, A. and Zaafouri, H. (2013) The Primitif Duodenal Adenocarcinoma. Journal Africain d'HépatoGastroentérologie, 7, 82-85.

[2] Akka, L., El Gannouni, N., C., I., El Bahlouli, A., Benhaddou, Z., Fadil, K., Krati, K., Essadki, O. and Ousehal, A. (2009) Primitive Adenocarcinoma of Duodenum: Two Cases Report and Review of Literature. Journal Africain d'Hépato-Gastroentérologie, 3, 231-234.

[3] Zaanana, A., Afchain, P., Carrere, N. and Aparicio, T. (2010) Small Bowel Adenocarcinoma. Gastroentérologie Clinique et Biologique, 34, 371-379.

[4] Krami, H. and Benzoubbeir, N. (1997) Primary Duodenal Adenocarcinoma. Maghreb Medicine, 63, 29-32.

[5] French National Institute of Gastroenterology. National Thesaurus of Gastrointestinal Oncology. Adenocarcinoma of the Small Bowel. (Consulted on 11/10/15)

http://www.snfge.org/sites/default/files/recommandations/tncd_chap-13-adenocarcinome-intestin-grele_2012-08-28.pdf

[6] Lepage, C., Bouvier, A.-M., Manfredi, S., Dancourt, V. and Faivre, J. (2006) Incidence and Management of Primary Malignant Small Bowel Cancers: A Well-Defined French Population Study. The American Journal of Gastroenterology, 12, 2826-2832. http://dx.doi.org/10.1111/j.1572-0241.2006.00854.x

[7] Foo, K.T., Sridharan, M., Ong, S.C. and Law, C.H.R. (1976) Low Primary Carcinoma of Duodenum a Case Report. Singapore Medical Journal, 2, 109-112

[8] Krami, H., Benzzoubeir, N., Ouazzani, L., Fadli, F., Ouazzani, H., Dafiri, N. and Bennani, A. (1997) Duodenal Primary Adenocarcinoma. Médecine du Magreb, 63, 29-32.

[9] Groves, C.J., Saunders, B.P., Spigelman, A.D. and Phillips, R.K.S. (2002) Duodenal Cancer in Patients with Familial Adenomatous Polyposis (FAP): Results of a 10 Year Prospective Study. Gut, 50, 636-641.

http://gut.bmj.com/content/50/5/636.full.pdf http://dx.doi.org/10.1136/gut.50.5.636

[10] Solej, M., D’Amico, S., Brondino, G., Ferronato, M. and Nano, M. (2008) Primary Duodenal Adenocarcinoma. Tumori, 94, 779-786.

[11] Malajati, H., Nassar, I., Bakkacha, O., Bouklata, S., Hammani, L. and Imani, F. (2008) Uncommon Etiological Jaundice. Feuillets de Radiologie, 5, 336-340.

[12] Pilleul, F., Crombe Ternamian, A. and Fouque, P. (2004) Examining the Small Bowel by Cross Sectional Imaging Techniques. Journal de Radiologie, 85, 517-530. http://dx.doi.org/10.1016/S0221-0363(04)97624-X

[13] Valette, P.J., Saurin, J.C., Ménard, Y., Henri, L., Fouque, P. and Chayvialle, J.A. (2000) Detecting Small Bowel Tumors by Entero-Imaging Technique. Gastroentérologie Clinique et Biologique, 24, A153.

[14] Eddeghai, S., Farouk, A., Diffaa, A. and Krati, K. (2014) Duodenal Primary Adenocarcinoma. Journal Africain d'Hépato-Gastroentérologie, 8, 115-118.

[15] Lowell, R.J.A., Rossi, R.L., Munson, L. and Braasch, J.W. (1992) Primary Adenocarcinoma of Third and Fourth Portions of Duodenum. Favorable Prognosis after Resection. Archives of Surgery, 127, 557-560. http://dx.doi.org/10.1001/archsurg.1992.01420050081010

[16] Lointier, P. and Beorchia, S. (1995) Duodenal Primary Adenocarcinoma. Revue du Praticien, 45, 271-273.

[17] Trede, M., Schwall, G. and Saeger, H.D. (1990) Survival after Pancreatoduodenectomy. 118 Consecutive Resections without an Operative Mortality. Annals of Surgery, 211, 447-458. http://dx.doi.org/10.1097/00000658-199004000-00011

[18] Onkendi, E.O., Boostrom, S.Y., Sarr, M.G., Farnell, M.B., Nagorney, D.M., Donohue, J.H., Kendrick, M.L., Lombardo, K.M., Haddock, M.G. and Que, F.G. (2012) Neoadjuvant Treatment of Duodenal Adenocarcinoma: A Rescue Strategy. Journal of Gastrointestinal Surgery, 16, 320-324. http://dx.doi.org/10.1007/s11605-011-1667-7 